\title{
DEL NEOBARROCHO O LA INESTABILIDAD DEL TACO ALTO (¿UN NEOBARROCO CHILENSIS?)
}

\author{
Soledad Bianchi \\ Universidad de Chile \\ soledadbianchi@vtr.net
}

Que "neobarrocho" es un vocablo compuesto que funde una buena parte del término "neobarroco" con las últimas letras de "Mapocho" está a la vista. Un "acrónimo" está "formado por la unión de elementos de dos o más palabras, constituido por el principio de la primera y el final de la última" (RAE). No obstante, más que ésta o que "palabra compuesta", preferiría utilizar los términos "palabra-valija” o "palabra-maleta" (¿existirán en español?), calco de la -tan gráfica y visual- expresión francesa "mot-valise" que, como "portmanteau [word]", es usada por Humpty Dumptyen el capítulo VI de A través del espejo y lo que Alicia encontró allí (1871), donde define, explicándole a la niña: "Hay dos significados empacados en una palabra".

¿Podría decirse que estos deslices entre idiomas serían similares a los roces lingüísticos que me llevaron a embarcarme con la voz "neobarrocho", cuando -en el Museo de Arte Contemporáneo- se presentó La esquina es mi corazón, el primer libro de crónicas de Pedro Lemebel, hace ya casi 20 años, el 29 de mayo de 1995?

Y menciono "voz" pues -como es habitual- mi lectura de "Pedro Lemebel, pupila equis de la transición" se oyó "a viva voz" - tal como los textos de Carmen Berenguer y de Martín Hopenhayn-, al añadirse la oralidad a nuestras escrituras, allí expuestas. (Esa "equis", de mi título, es ambigua: alude tanto a los "rayos equis" de las radiografías, que todo lo atraviesan, como a la "x" -repetida tres veces- del anuncio de ciertas películas casi prohibidas). Ahora, me piden que explique el término "neobarrocho", que utilicé entonces, y me vuelvo a arriesgar y vuelvo a enfocarlo, recortando algunos párrafos del documento de 1995:

[En] estas narraciones... hablaba yo de demasía, densidad, aglutinación y aglomeramiento, pensando en la abundancia de adjetivos, en la concentración de cada frase (el desarrollo de muchas de ellas podría redundar, creo, en una crónica completa), en el manipuleo con las palabras que traviesamente, y con placer, son atracadas, torcidas, invertidas, disfrazadas, hasta que expresen lo que se busca, por el imperioso deseo de exhibir todo lo que se quiere, absolutamente todo. Es frecuente que estas "crónicas urbanas" 
se excedan por excesivas y porque si bien pueden referir a un lugar específico, no cabe duda que se abren y "hablan" de mucho más, así como sus títulos, metafóricos, muy penetrantes, tan sugerentes como una seña, un aviso para comprender esta mirada, como de fin de fiesta, a esta sociedad tan neo-liberal, pero tan poco libre y liberada. Tal vez esta prosa exuberante donde la puntada se complica, y se viste la frase para desvestir lo que se mira, podría ligarse con el exceso de la vestimenta y el maquillaje travesti. ¿Por qué no pensar, además, que ese espesor y concentradísima densidad podría ser impuesto por el género de la crónica periodística que obliga a acatar metros precisos? De pronto, José Lezama Lima se (me) viene a la mente, por la lujuria, no sólo verbal, de su propia obra, y por su afición y estudios sobre el barroco. También, como un simulado eco, el neo-barroco, de su compatriota cubano Severo Sarduy. Más cerca, el argentino Néstor Perlongher se reconoció acompañante de los cubanos, y habló del neo-barroso para aludir a su hacer y su entorno, a su hacer en su entorno, el atigrado y oscuro Río de la Plata, y todo nuestro barro y otras mezclas y menjunjes latinoamericanos. Sospecho que Pedro Lemebel sigue este trayecto, y veo que camina, por el Parque Forestal, del brazo del asmático viejo, del espejeante Sarduy, y del joven que el sida se llevó. Veo al chileno conversándoles: divertido, les hace un guiño, y mientras los cuatro enmascaran vocablos, yo le cuchicheo: "neobarrocho", y Pedro lo agarra al vuelo y copuchea: "Eso es, neobarrocho, niñas". Sí, concibo el estilo de Pedro Lemebel como "neo-barrocho", por un barroco que llegando a Chile pierde el fulgor isleño y la majestuosidad del estuario trasandino, al empaparse y ensuciarse en las aguas mugrientas del río Mapocho que recorre buena parte de Santiago, tal como estas crónicas, poco recorridas por él. El río Mapocho que apenas se adivina; casi invisible por el smog; silenciado, también, por la rápida carrera de los automóviles; más gato que jaguar con su esmirriada corriente, ¡tan reprimido!, buen reflejo de esta fotocopia gris del Edén (fotocopia borrosa, a su vez, de la "copia feliz del Edén", esa idílica imagen con que la Canción Nacional percibe nuestro territorio), lugar de escape y muerte en "Anacondas en el parque", de La esquina es mi corazón, este paseo por escenografías y escenas, variadas y diferentes, contempladas desde la diferencia, expresadas en textos diferentes, porque La esquina es mi corazón cuestiona identidades, cuestiona géneros -el literario, el sexual-, además de diversificar una ciudad segmentada que se pretende cada día más uniforme y homogénea, y de diversificar una narrativa chilena demasiado auto-complacida, porque donde Pedro Lemebel pone el ojo, penetra profundamente... y duele.

"[L]o expresado no existe fuera de sus expresiones", señala Deleuze, en El Pliegue (51) $\mathrm{y}$, en estos párrafos, enumero rasgos de la expresión de Pedro Lemebel y, aunque no los califique ni clasifique, siempre, como "sustitución", "proliferación", "condensación", "parodia", "cita", "reminiscencia" o "juego", es indudable que a éstos estoy aludiendo, pues hay vecindades y, en ocasiones, hasta coincidencias, con procedimientos, "procesos" (Sarduy) y "operaciones" (Sarduy, Deleuze) percibidos, y etiquetados, entre otros, por "El barroco y el neobarroco", ordenado estudio del metódico Severo... Sarduy.

Hay veces en que, incluso, los retruécanos, de las crónicas de Lemebel, parecieran seguir los consejos de "De la agudeza en apodos", de Baltasar Gracián, en Agudeza y Arte de ingenio (1648). E indico que traspaso estas formalidades de "un tipo de realización verbal, compleja, espiralada, no perfilada que podemos designar como 'barroca'". 
(Jitrik 28), porque, a mi entender, usándolas, el trabajo de Pedro Lemebel -sea barroco, neobarroco o neobarrocho- las rebasa ${ }^{1}$.

"La tendencia del Barroco a la apoteosis constituye la contrapartida de su modo específico de contemplar las cosas", afirma Walter Benjamin en El origen del drama barroco alemán. "La falta de tal apariencia luminosa [de las cosas] puede considerarse uno de los rasgos más severos de toda la poesía lírica barroca. Y lo mismo sucede con el drama"(173), añade. Y yo, sin temerle ni a los saltos temporales ni de espacios ni de géneros literarios, imagino que las crónicas de Pedro Lemebel podrían considerárseles contiguas, es decir, barrocas, por su percepción de numerosas pérdidas, desengaños, desencantos, desesperanzas y decadencias, apuntadas con tono triste, con dejos melancólicos, encontrándose y complementándose, sin anularse, con la ironía, la parodia, el humor, el exceso, provocadores de sonrisas y hasta de risas.

Asimismo, explico (y puntualizo que, recién, no quise usar el término "aclaro" pues la claridad no era del gusto del Barroco, sino el claroscuro su predilecto). Explico, entonces, que si bien en el largo fragmento citado me centro en La esquina es mi corazón, desde el presente desplazo el margenal más amplio horizonte actual, de siete volúmenes de crónicas y una novela -Tengo miedo torero (2001) (que no consideraré)-, porque siguen un rumbo semejante, con miradas y estilo semejantemente rumbosos... y barrocos, neobarrocos y neobarrochos.

Vuelvo sobre mis pasos y sobre el "neobarrocho", e invento (après-la-lettre, es decir, ahora) y di-vago que, tal vez, imaginé la palabra porque el Museo de Arte Contemporáneo, donde se presentó La esquina es mi corazón, está cerca del río Mapocho. O, tal vez, más probablemente, porque me pareció una deriva y traslación lógica (¿o loca?) desde el término "neobarroso", utilizado por Perlongher, para señalar la "expresión rioplatense" de una "poética neobarroca". Luego, solo se trataba de cruzar la Cordillera, trazar una filiación y considerar a Lemebel integrando una genealogía, nada de arbórea, porque su obra podría considerarse una raicilla, entre otras, de una red entre cuyos muchos nudos puede reconocerse a los ya destacados Lezama Lima, Sarduy y Perlongher, cada uno a su modo, con sus distinciones, en sus escenarios, en sus territorios, pero todos reflejando y haciendo reflejar, provocando y acogiendo ecos, deslizándose desde Cuba, La HabanaParís, a Buenos Aires y, en su travesía, atracar en las santiaguinas orillas del Mapocho y situarse en ellas, delineando -con Pedro- un mapa otro, diferente y de la diferencia. Fluyendo del Barroco al Neobarroco (americano ya), al Neobarroso "transplatino", al Neobarrocho.

Se trataba de navegar entre trazos barrocos, desde el mar y la isla al Río y desde el Río (mayúsculo) al río santiaguino, del Río de la Plata al río Mapocho y, tal como Perlongher

Por lo demás, en Historia social de la literatura y el arte (1969), Arnold Hauser considera ese momento artístico sin "carácter unitario". Del mismo modo, en 1987, Aurora Egido lo concibe como: "un estilo de época que no es uniforme, sino vario, como la misma poética que / lo impulsara" (54-55), y hasta diferencias podrían advertirse, según ella, dentro de la producción de un mismo -y "cambiante"- autor. 
llama "apelativo paródico" a su ocurrencia, yo diría que el juego de palabras, usado por mí, está entre el chiste (del eco) y un guiño cómplice, pues apunta a las particularidades que tiene el neobarroco "practicado" en estas riberas, esto es: en los bordes de la "larga y angosta faja de tierra" que es Chile y en las crónicas de Lemebel -con frecuencia, urbanas y santiaguinas- percibimos el neobarrocho, con gran nitidez y singularidad, en su lenguaje, en los espacios que transita, en los personajes y situaciones aludidas y... en otras características diversas.

No obstante, el vocablo "neobarrocho" puede prestarse a equívocos porque sus márgenes parecen tan ajustados como los del céntrico torrente cuando fluye por esa zona de la ciudad, puesto que el río Mapocho apenas franquea la capital y comprenderlo literalmente significaría estrecharse al centralismo. Siendo así, habría que desplegar puentes: del centro a las regiones y viceversa, y entre ellas, asimismo, y surgiría un barroco andino que, además, no se limitaría a Chile, evidenciando que las afinidades estéticas no obedecen ni se rigidizan en las fronteras políticas... Sin embargo, vayamos contra la corriente y rememos hacia atrás para encontrar el origen de "Mapocho". Se dice que también es un "acrónimo": la contracción de "mapu-che: gente de la tierra" y "co: agua, río": "río de los mapuche" (Moesbach), significaría, entonces. Entre conjeturas y titubeos, podría especularse estar frente a un término abarcador y mucho más amplio y extendido, es decir, suponer el "Mapocho" -"el agua o el río de los mapuche"- no restringido solo a la ciudad de Santiago, y este ensanchamiento lo confirmarían otros desbordes etimológicos que remiten, simplemente, a una deformación sonora de "mapuche" (che=gente; mapu=tierra) o, de modo menos sencillo, a: mapu-chun-ko, agua o río que se pierde en la tierra (León Echaiz 30-31).

Igualmente, "El río Mapocho (o 'el Sena de Santiago, pero con sauces')" fluctúa entre lo local y el país: "Porque este río, símbolo de Santiago, se descuelga desde la cordillera hasta el mar, cortando el flaco mapa de Chile en dos mitades, y en su recorrido nervioso, atraviesa todas las clases sociales que conforman la urbe" (Esquina 119).

Con todo, en los pasos y poses de sus paseos (fantaseados y vividos), más que flâneur, para mí, Lemebel es un caminador, un errabundo, un callejero, un trotacalles, un caminante privilegiado y, en sus andanzas y crónicas, el "zumbar pedregoso del río Mapocho" (Cafiola 63) no es tan ensordecedor, ni sus puentes, tan manifiestos; escenografía reconocible como telones de fondo: tal vez porque de tanto verlos casi no se perciben ni se necesitan explicitar; tal vez porque no fue el decorado - paisaje/no-paisaje- primero visto por estenarrador.

Zanjón de la Aguada (2003), uno de los cauces, uno de los canales que desembocan en el Mapocho, es retenido, en cambio, hasta con un título de volumen. Es el nombre, por lo demás, de una zona capitalina, lugar de residencia del niño-Lemebel, futuro cronista de... "Zanjón de la Aguada (crónica en tres actos)": "Primer acto": "La arquelogía de la pobreza"; "Segundo acto": "Mi primer embarazo tubario"; "Tercer acto": "Las memorias del Carne Amarga" y "Epílogo": "La nostalgia de una dignidad territorial" (13-23), que finaliza: "Para mejor vivir la escarcha indiferente de estos tiempos, vale dormirse soñando que el Tercer Mundo pasó por un zapatito roto, que naufragó en la corriente del Zanjón de la Aguada, donde un niño guarisapo nunca llegó a ser princesa narrando la crónica de su interrumpido croar" (23). 
Pero, fuera de ser un símbolo urbano y chileno, ¿por qué aproximar el poco exuberante Mapocho al Barroco? Abajo, el río Mapocho, tajo y tatuaje en movimiento (Perlongher prefiere el "tajo", del narrador argentino OsvaldoLamborghini, al "tatuaje" del cubano Sarduy): corrientes aguas, turbias, nada cristalinas que, canalizadas ( $¿$ tan encauzadas por los poderes como nosotros, los chilenos?), se desplazan rápido, muy rápido, en exiguas olas que ocultan basura, sobras, inmundicias, restos, escombros, que (a)parecen vomitados en sus sucias playas de piedra, para comida de desorientadas gaviotas. "Invasión de pliegues, orlas iridiscentes o drapeados magníficos...”, así entiende el neobarroco Perlongher y, a mí, me hubiera gustado describir los tumbos del río con esas palabras, pero es imposible y, ya lo sabemos: ni tan imponente ni tan amplio ni tan traslúcido ni tan amigable, el río Mapocho que integra el "barrocho" pasando por el "barro", no es majestuoso. Y en la (p)referida tonalidad del claroscuro barroco, yo aproximo al "Mapocho" a su ribera menos clara, al punto que medio traicionero y obscuro se le divisa al inicio del ya conocido escrito de Lemebel que lleva el nombre del caudal:

En verano parece una inocente hebra de barro que cruza la capital, un flujo de nieves enturbiadas por el chocolate amargo que en invierno se desborda, desconociendo límites, como una culebra desbocada que arrasa en su turbulencia las casas de ricos y pobres levantadas en sus orillas... (119)

No es raro, tampoco, y ya lo dije, que se le relacione con muerte, y no solo por haber recibido cadáveres los primeros tiempos posteriores al Golpe de Estado, los nunca olvidados muertos del Mapocho ("Un ahogado pensativo a veces desciende" es un poema, de esos días, de Oscar Hahn en Arte de morir).

Lejos del esplendor, en los murmullos y rumores de sus ondas (que, cual pliegues, con frecuencia algo esconden y muestran, simultáneamente, en fragmentos, replegándose y desplegándose), el tedio triste de Pedro Lemebel se tiñe de nostalgia ("El flaco Miguel”, y más). Y en los murmullos y rumores retumba, igualmente, la melancolía: melancolía de la caducidad, de las mudanzas, del tránsito: "nuestras vidas son los ríos /que van a dar a la mar, / que es el morir", nos recuerda Jorge Manrique (1440-1479) en las “Coplas a la muerte de su padre". Cuatro siglos y medio después, el poeta chileno José Ángel Cuevas reconoce: "todos tendremos que morir alguna vez / y el Mapocho no va a detener su discurso" ("Introducción a Santiago": 1982-1987). De todos modos, y sabiendo que la naturaleza no tiene sentimientos ni voluntad, a pesar de "sus" pesares, el Mapocho no es feo; y en sus pasares, el Mapocho no es feo (me apropio de estas palabras de Lemebel en "Martita Primera (o "esos grandes botones de la moda presidencial")", donde, en un guiño irónico con un hilarante ritornello, cada ciertos párrafos, repite con gracia: "La Martita no es fea" (Perlas), en alusión a la "Primera Dama", Martita Larraechea, esposa del Presidente democristiano, Eduardo Frei Ruiz-Tagle: 1994-2000.

Regreso al "neobarrocho" y lo relaciono con límites y me pregunto, asimismo, qué deslindes marca el Mapocho. En la historia de Santiago, el río fue frontera entre sus opuestos sectores norte y sur: La Chimba, territorio de los extramuros y del desorden, y el centro histórico y su regulada cuadrícula, respectivamente (Márquez y Truffello). Ya sabemos de qué lado está el "neobarrocho", reconociendo, eso sí, que a pesar de 
conservar desigualdades, hoy, las fronteras son más porosas y transitables y no tienen la estrictez ni son tan infranqueables como en el pasado ${ }^{2}$. Y Pedro Lemebel, sin fatigarse, yendo del Mapocho-p'allá-del-Mapocho-p'acá, las atropella, desata y desbarajusta una y otra vez en sus escritos y en su escritura.

Cambiando el foco, en Medusario, Roberto Echavarren precisa, con esmero, algunos de los confines de la poesía "neobarroca", mas esos contornos genéricos pueden expandirse a la "impura” práctica neobarroca, en general: “... ora coloquial, ora opaca, ora metapoética. Trabaja tanto la sintaxis como el sustrato fónico, las nociones como los localismos. Y pasa del humor al gozo" (13). Fronteras serpenteantes y nómadas son, entonces, las del Mapocho, tan movibles y fugaces como las del "neobarrocho".

Entre bordes y desbordes, en este trayecto por las crónicas de Pedro Lemebel, creo haber (de)mostrado ciertos rasgos "neobarrochos" que no se limitan solo a la "forma" o/y a un estilo sino que están traspasados, y son inseparables, me parece, de un cierto tono, un ánimo, un dejo, propios del barroco y del neobarroco... y del neobarrocho, y tampoco se limitan solo a su escritura. Por este motivo, ampliaré, ahora, mi perspectiva para esbozar una reducida sinopsis de menciones y miraré hacia otros autores y textos neobarrochos, literarios o no. "Se trata - podría decir con Perlongher- de esbozar una cartografía intensiva que dé cuenta del arco neobarroco, cuyos límites tan difusos resulta harto arriesgado trazar" (30).

"Santiago es una esquina, Santiago no es el gran mundo..." (Cafiola 39), aclara, con precisión, Lemebel. Chile es una esquina, Chile no es el gran mundo, amplificaría un eco. Y, por supuesto, no puede haber un barroco en cada esquina. Hay que cuidarse, además, de una tentación que lleve -cual obsesivo entomólogo- a etiquetarlo todo. Entonces, por temor a la diversidad, cualquier producción -no solo escrita-difícil, enrevesada o, como apunta Echavarren, que "promueve la conexión gramatical a través de una sintaxis a veces complicada" (13), sería posible de ser tildada de "neobarroca" o "neobarrocha".

Algunos aseguran que en Chile no existió el Barroco y para confirmarlo o negarlo habría que volver a mirar, a re-leer, a escuchar nuevamente y desde hoy. Por mi parte, yo me aproximo, en cambio, a quienes señalan la novela de José Donoso (1924-1996), El lugar sin límites (1966), como "neobarroca" (Sarduy, Perlongher y otros)/ "neobarrocha". Del mismo autor, yo añadiría: El obsceno pájaro de la noche (1970). El escritor argentino menciona, asimismo, a Diamela Eltit (1949), y nombra a Diego Maquieira (1951), Raúl Zurita (1950 -invitado este año al ciclo, "La máquina barroca", en la Universidad de Nueva York-) y Gonzalo Muñoz (1956), entre los poetas así calificados. Incluso, escritos de estos dos últimos integran la "muestra" Medusario.

Para Echavarren: "Los poetas neobarrocos ... pasan de un nivel de referencia a otro, sin limitarse a una estrategia específica, o a cierto vocabulario, o a una distancia irónica fija. Puede decirse que no tienen estilo, ya que más bien se deslizan de un estilo a otro sin volverse los prisioneros de una posición o procedimiento", dice (14). Pienso la

2 "El mundo fluvial no se me entregaba ni se abría de buenas a primeras" (107), dice Toño, el protagonista, en la "novela autobiográfica", El río, de Alfredo Gómez Morel (1962). 
descripción anterior en su desemejanza con la prosa: más representacional, en muchas ocasiones; pienso en la crónica, más mimética y hasta informativa. No obstante, no hay que olvidar nunca cuán serpenteantes son las fronteras textuales y cuán retorcidos pueden ser los hilos de las filigranas de los textos neobarrochos: como la exuberante escritura de Tomás Harris (1956) y sus universos de delirios; la de Javier Bello (1972), con la muerte como trasfondo de su poesía. Mientras, en los versos de Sayal de pieles (1993), de Carmen Berenguer (1946), el significante de palabras de un lenguaje, inútil para comunicarse, se refocila, reflejo, en el goce del sonido.

En teatro, se me ocurre sugerir como "neobarrochos" a algunos dramaturgos y directores que, desde la experimentalidad y múltiples actividades (instalaciones, actuación, danza, performas, etc.), marcaron la época de la dictadura. Sin detenerse en ella, los aportes de Vicente Ruiz (¿1955?), Alfredo Castro (1955) y Ramón Griffero (1954) han continuado, cada uno a su manera y desde sus personales intereses y perspectivas. Me restrinjo a sus nombres, sin dudar que debe haber muchos otros "teatristas" que transitan y trabajan barroco(s) desde el Mapocho.

Mirando las artes visuales, no puedo dejar de detenerme en las fotos de Demian Schopf (1975), reunidas en la exposición "Los tíos del diablo" (2013), donde aparecen bailarines de La Tirana y de Carnavales de Bolivia. Sus trajes y todo lo que significa adquirirlos en trabajo y gasto, además de su boato y recargada pulcritud, contrasta con la basura ambiental que, en su exceso, se aproxima a lo recargadas que son las vestimentas. Superabundancia y desperdicios: rasgos propios del espacio barroco, según Sarduy. "Me interesa profundizar y resignificar algunas manifestaciones culturales contemporáneas del neobarroco latinoamericano", reconoce Schopf, y así lo ha evidenciado en sus diferentes muestras.

Figurativa es la pintura de Guillermo Lorca (1984) y sus escenas hiperrealistas -naturalezas muertas, interiores, retratos, etc.- desbordan de pliegues. No obstante, en la "perfección", a pesar de ella o, tal vez, a causa de ella, se adivina una leve grieta, una trizadura, quizá cierto sarcasmo, anunciador -en susurros- que no todo lo que se percibe es delicadeza y hermosura por la próxima cercanía de algo carcomido, inquietante y hasta perverso.

También “arma” y juega con narraciones, Marcela Trujillo (1969), pintora y dibujante y escritora de guiones de historietas de un "neobarrocho" - digámosle- sucio, con harto barro y borra por el atiborramiento y gozoso revoltillo de imágenes, colores y líneas hasta el último de sus rincones "Estoy de cabeza pintando y dibujando naves espaciales orgasmoecnotrónicas, superheroínas con trajes altiplánicos en paisajes futurísticos tecno-orgánicos. Estoy mezclando imágenes húmedas y asquerosas del interior del cuerpo humano con objetos metálicos y brillantes de la tecnología súper avanzada, la nanotecnología, los microchips y todo eso" (en entrevista con Sergio Paz).

Regreso a la literatura y a novelas recientes. Imagino, por lo demás, menos impertinente calificar de "neobarrocho" (u otro membrete) un texto que un autor, si no se sigue su producción paso a paso, huella a huella. Quiero referirme a El Tarambana (2013). Esta primera narración extensa, de Yosa Vidal (1981), está escrita como novela picaresca, en estructura y lenguaje, pero con las incógnitas, problemas e incertidumbres de una 
actualidad chilena, abarcadora de las casi cinco últimas décadas. Con variados fingimientos y penetrante humor -que, en ocasiones, lleva y llega a las carcajadas-, el diálogo con esta forma literaria, característica del Barroco del siglo XVII, exhibidora del engaño y el desengaño y del culto a las apariencias, ayer y ahora, le sirve a este -neobarrochorelato contemporáneo para mostrar, hacer reparos, ironizar, mientras los desplazamientos del travestido protagonista evidencian realidades dispares que desbordan en mucho los surcos del Mapocho, inundando y extendiéndose a un país complejo y desigual, Chile. (¿Será que "La nuestra es agua de río mezclada con mar", como entona Celia Cruz y Los Fabulosos Cadillacs, en "Vasos Vacíos"?).

"El espacio barroco es el de la superabundancia y el desperdicio (...), el lenguaje barroco se complace en el suplemento, en la demasía y en la pérdida parcial de su objeto. O mejor: en la búsqueda, por definición frustrada, del objeto parcial (...) (la saturación sin límites, la proliferación ahogante, el horror vacui) preside el espacio barroco.”, afirma Sarduy (El barroco 32), y pareciera estar refiriéndose a Hijos de la trampa (2013), de Dany Palma (1960), el creador de las underground "Fiestas Spandex", de la década del 90, contadas, además, en su novela, donde el gozo no cesa. Al leerla, se va reconociendo, uno a uno, cada procedimiento que Sarduy, y otros estudiosos del neobarroco, identifican como sus atributos.

A pesar de la presencia de múltiples personajes y de sus actos, sería posible convenir que, aquí, el protagonista es el lenguaje. Gozo del lenguaje y lenguaje del gozo: los sonidos, la acústica, la música de las palabras, las sinestesias; sinónimos y redundancias; deformaciones e invento de vocablos; paseo por híbridos campos semánticos; ambigüedades; revoltijo de idiomas, se usan, con frecuencia, para decir el cuerpo con un lenguaje que hace visible el cuerpo del lenguaje cuando éste se encarna, se hace opaco, tiene consistencia y casi independencia. Fricción de cuerpos y sus partes, fricción de lenguajes, fricción de verbos y voces: lenguaje del erotismo y erotismo del lenguaje donde el deseo, la sensualidad y la pasión son vividos y experimentados, y narrados, sin distancias, ni idealizados ni embellecidos, con franqueza y hasta explícitamente brutal -en vocabulario (cotidiano, en sus diversos registros), en acciones, en perspectivas y comentarios-, transformando esta novela (muy) autobiográfica -tal vez, memoria novelada-, no sé si en una excepción totalmente definitiva dentro de la narrativa chilena actual, pero sí en un texto bastante destacable en su realismo "neobarrocho": "-. Ya, poh, yo también tengo ganas, ¿te la sacudo? / La noche es un carrusel a ritmo de mis ansias; giren moscas, y abran sus alas hasta alcanzar nubes azucaradas" (181).

Con Benjamin podría decirse que en Hijos de la trampa hay una "... manera barroca de plasmar la forma, que se complace en las vacilaciones, entregándose a interminables preparativos y rodeos" (176), y son tantos los deslizamientos, los dobleces, los inicios, los retrocesos, los enredos, y es tanta la materia a contar y la rapidez de la narración que hay momentos en que el lector se pierde entre las intrincadas y laberínticas historias, pero termina por coger el hilo, tirarlo y volver a penetrarlas y continuar la lectura y su placer: "Este es el gozo que rara vez propago. El gozo de recordar a mis muertos, uno a uno", así, entre lágrimas y risas y noches y días y bailes y entierros y brillos y fiestas, como en un escenario, como un decorado con luces estroboscópicas, como en un caleidoscopio, se va desplegando y replegando el espectáculo claroscuro de esta loca escritura loca (el 
espejo refleja: "cola") y neobarrocha de Daniel Palma, imposible de elaborarse -a mi entender-sin la pluma (y las plumas), las líneas y las travesías - urbanas y textuales- del precursor Pedro Lemebel.

He querido dejar para el final la inestabilidad, una nota barroca y neobarroca, aludida con frecuencia por los investigadores (Calabrese, Guerrero, Sarduy). Sin duda, podría estudiar la inestabilidad en variados textos neobarrochos, más numerosos, incluso, que los recién marcados, pero prefiero advertir otro ángulo. Más atractivo, me resulta, fijarme en la figura de Pedro Lemebel.

Desde alguna esquina oigo sus pisadas. Miro de reojo y veo a Pedro calzando unos encumbrados tacos aguja. Él optó por usarlos y sacarlos del closet porque le gustaban y porque, además, quiere llamar la atención, son un llamado de atención. Son un llamado de atención hacia todo lo que Lemebel desea -y necesita- hacer notar y visibilizar, como lo muestra en su literatura y en sus trabajos visuales, inseparables de su persona y su trayectoria personal. Nadie puede quedar indiferente ni puede simular que no (lo) ve, ni en el estudio de televisión, ni en la calle, ni en un teatro, ni en una manifestación política, ni en una galería de arte o donde sea el espacio elegido -por él- para quebrar hipocresías y convencionalismos y exteriorizar sus preferencias.

Lemebel hace una opción por "la inestabilidad del taco alto" y, a pesar de su bamboleante caminar, sus caminatas son seguras, pero, al mismo tiempo, nada fáciles ${ }^{3}$. "Tiendo a confundir memoria e historia, memoria y sueño, memoria y deseo, en fin... al final no me queda claro si lo soñé, me ocurrió o lo ficcioné, aunque la ficción no me queda. En fin, es el vértigo inestable de la escritura" (entrevista con Cossio).

Lemebel hace una opción por "el taco alto" que le hace observar y elaborar las realidades que le interesan desde perspectivas diferentes, menos fijas, más oscilantes y mutables, sin rigideces, opuestas a los prejuicios con que él es percibido por quebrantarlos al impugnar cartabones definitivos, no solo en su apariencia sino, también, en sus producciones porque - para él y en éstas- arte y vida son unidad. Nada extraña, entonces, que entre sus lectores jóvenes exista un "Colectivo Lemebel" en el masculino Liceo Barros Borgoño y que "Las Putas Babilónicas" sea el nombre de un grupo de estudiantes del Liceo Lastarria, de varones, que realiza acciones de arte con sus integrantes de "boquitas pintadas" de rojo intenso, vestidos con las camisas y corbatas de sus uniformes escolares, y con medias y altísimos y delgados tacones (uno de sus seguros referentes serían "Las Yeguas del Apocalipsis", la dupla artística integrada por Lemebel y Francisco Casas, de creativas actividades durante la dictadura y la primera década de la democracia, en especial). Ambos conjuntos se reconocen deudores de Pedro Lemebel y reconocen, igualmente, su atrevimiento que les permitió atreverse, y así lo manifestaron en el coloquio Después del desastre: cuatro décadas de narrativa chilena (1973-2013), realizado en octubre del

3 Llama mi atención el cambio de significado que hace Lemebel al usar la minúscula para "mariquita". Como se sabe, "Adiós, Mariquita linda" es el nombre de una canción dedicada a una mujer de ese nombre y su compositor fue: Marcos Augusto Jiménez Sotelo (Tacábaro, México, 1882-1944). 
2013, en la Facultad de Filosofía y Humanidades, de la Universidad de Chile. Y es que, como dice Sarduy en una entrevista con Jean-Michel Fossey:

Contrariamente al lugar común que presenta al Barroco como un simple deseo de evasión, de oscuridad o de exquisitez, el exceso barroco tiene hoy una función más precisa y radical: ser barroco, hoy, significa amenazar, juzgar y parodiar la economía burguesa, basada en la administración tacaña -o, como se dice, "racional"- de los bienes, en el centro y fundamento mismo de esa administración y de todo su soporte: el lenguaje, el espacio de los signos, cimiento simbólico de la sociedad y garantía de su funcionamiento (16).

Y es con este Barroco que se inscribe Pedro Lemebel, quien ha optado por un quehacer artístico activo y provocador, donde una explícita política sexual se engarza con su política textual en escritos que, en su primer momento, en tiempos cercanos al mini-boom de la llamada "nueva narrativa chilena", con "la inestabilidad del taco alto" desequilibraron una literatura bastante homogénea y remolona, que tendió a rechazarlos o, para ser precisos, sus autores intentaron parapetarse, desestimándolos. Hoy, sin embargo, nadie dudaría que Pedro Lemebel ocupa, con firmeza, un espacio en la literatura chilena, enriqueciéndola en diversidad con sus -siempre alertas- narraciones de plumazos neobarrochos.

\section{BIBLIOGRAFÍA}

Benjamin, Walter. El origen del drama barroco alemán. Madrid: Taurus, 1990.

Berenguer, Carmen. Sayal de pieles. Santiago: Francisco Zegers Editor, 1993.

Cuevas, José Ángel. "Introducción a Santiago". Adiós muchedumbres. Santiago: Editorial América del Sur, 1989.

Deleuze, Gilles. El Pliegue. Leibniz y el Barroco. Barcelona: Paidós, 1989.

Diccionario Mapudungun. Lengua Mapuche. Santiago: Ediciones Olimpo, 2003.

Echavarren, Roberto. "Prólogo". Medusario: Muestra de poesía latinoamericana. Eds. R. Echavarren, José Kozer y J. Sefamí. México: FCE, 1996.

Egido, Aurora. Fronteras de la poesía en el Barroco. Barcelona: Crítica, 1990.

Gómez Morel, Alfredo. El río. Santiago: Talleres de Arancibia Hnos., 1962.

Guerrero, Gustavo. La estrategia neobarroca: Estudio sobre el resurgimiento de la poética barroca en la obra narrativa de Severo Sarduy. Barcelona: Edicions del Mall, 1987.

Jitrik, Noé. El balcón barroco. México: UNAM, 1988.

Lemebel, Pedro. La esquina es mi corazón. Crónica urbana. Santiago: Cuarto Propio, 1995. Loco Afán. Crónicas de sidario. Santiago: LOM, 1996.

De perlas y cicatrices. Crónicas radiales. Santiago: LOM, 1998.

Tengo miedo torero. Buenos Aires: Seix Barral, 2002.

Zanjón de la Aguada. Santiago: Seix Barral, 2003. 
Adiós mariquita linda. Santiago: Sudamericana, 2004. Serenata Cafiola. Santiago: Seix Barral, 2008. Háblame de amores. Santiago: Seix Barral, 2012. “'Mi escritura no es vitrina': Lemebel”. Entr. Héctor Cossio. El Mostrador (27 octubre 2013).

León Echaiz, René. Historia de Santiago. Tomo I: La Colonia. Santiago: Municipalidad de Santiago, 1975.

Márquez, Francisca y Ricardo Truffello. "Geografías de un territorio de frontera: La Chimba, Santiago de Chile. Siglo XVII -XXI”. Revista de Geografia Norte Grande 56: 75-96.

Moesbach, P. Ernesto Wilhelm de. Voz de Arauco. Explicación de los nombres indígenas de Chile. 1944. Padre Las Casas: Imprenta San Francisco, 1976.

Palma Sepúlveda, Dany. Hijos de la trampa. Santiago: Asterión, 2013.

Paz, Sergio. "Marcela Trujillo, la mujer maravilla". Revista Ya de El Mercurio (21 septiembre 2010).

Perlongher, Néstor. "Prólogo". Medusario: Muestra de poesía latinoamericana. Eds. R. Echavarren, José Kozer y J. Sefamí. México: FCE, 1996.

Sarduy, Severo. "Severo Sarduy: máquina barroca revolucionaria". Entr. Jean-Michel Fossey. En Jorge Aguilar et al. Severo Sarduy. Madrid: Fundamentos, 1976. 15-24. El barroco y el neobarroco. Buenos Aires: Cuenco de plata, 2011.

Schopf, Demian. "Presentación” en folleto sobre Galería Patricia Ready.

Vidal, Yosa. El Tarambana. Santiago: Tajamar, 2013. 